NASA/TM-2000-209291

Preparation of Ion Exchange Films for Solid-Phase Spectrophotometry and Solid-Phase Fluorometry

Carol M. Hill, Kenneth W. Street, and Warren H. Philipp

Glenn Research Center, Cleveland, Ohio

Stephen P. Tanner

University of West Florida, Pensacola, Florida 
The NASA STI Program Office ... in Profile

Since its founding, NASA has been dedicated to the advancement of aeronautics and space science. The NASA Scientific and Technical Information (STI) Program Office plays a key part in helping NASA maintain this important role.

The NASA STI Program Office is operated by Langley Research Center, the Lead Center for NASA's scientific and technical information. The NASA STI Program Office provides access to the NASA STI Database, the largest collection of aeronautical and space science STI in the world. The Program Office is also NASA's institutional mechanism for disseminating the results of its research and development activities. These results are published by NASA in the NASA STI Report Series, which includes the following report types:

- TECHNICAL PUBLICATION. Reports of completed research or a major significant phase of research that present the results of NASA programs and include extensive data or theoretical analysis. Includes compilations of significant scientific and technical data and information deemed to be of continuing reference value. NASA's counterpart of peerreviewed formal professional papers but has less stringent limitations on manuscript length and extent of graphic presentations.

- TECHNICAL MEMORANDUM. Scientific and technical findings that are preliminary or of specialized interest, e.g., quick release reports, working papers, and bibliographies that contain minimal annotation. Does not contain extensive analysis.

- CONTRACTOR REPORT. Scientific and technical findings by NASA-sponsored contractors and grantees.
- CONFERENCE PUBLICATION. Collected papers from scientific and technical conferences, symposia, seminars, or other meetings sponsored or cosponsored by NASA.

- SPECIAL PUBLICATION. Scientific, technical, or historical information from NASA programs, projects, and missions, often concerned with subjects having substantial public interest.

- TECHNICAL TRANSLATION. Englishlanguage translations of foreign scientific and technical material pertinent to NASA's mission.

Specialized services that complement the STI Program Office's diverse offerings include creating custom thesauri, building customized data bases, organizing and publishing research results ... even providing videos.

For more information about the NASA STI Program Office, see the following:

- Access the NASA STI Program Home Page at http://www.sti.nasa.gov

- E-mail your question via the Internet to help@sti.nasa.gov

- Fax your question to the NASA Access Help Desk at (301) 621-0134

- Telephone the NASA Access Help Desk at (301) 621-0390

- Write to:

NASA Access Help Desk

NASA Center for AeroSpace Information 7121 Standard Drive

Hanover, MD 21076 
NASA/TM-2000-209291

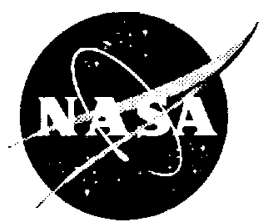

\section{Preparation of Ion Exchange Films for Solid-Phase Spectrophotometry and Solid-Phase Fluorometry}

Carol M. Hill, Kenneth W. Street, and Warren H. Philipp

Glenn Research Center, Cleveland, Ohio

Stephen P. Tanner

University of West Florida, Pensacola, Florida

National Aeronautics and

Space Administration

Glenn Research Center 


\section{Acknowledgments}

The authors would like to thank the NASA Glenn Research Center Director's Discretionary Fund for the initial funding of this research and the ASEE summer faculty fellowship program for summer support (SPT).

Trade names or manufacturers' names are used in this report for identification only. This usage does not constitute an official endorsement, either expressed or implied, by the National Aeronautics and Space Administration.

Available from

7121 Standard Drive

Price Code: A03
National Technical Information Service 5285 Port Royal Road Springfield, VA 22100

Price Code: A03 


\title{
PREPARATION OF ION EXCHANGE FILMS FOR SOLID-PHASE SPECTROPHOTOMETRY AND SOLID-PHASE FLUOROMETRY
}

\author{
Carol M. Hill \\ The Goodyear Tire and Rubber Company \\ Topeka, Kansas 66601 \\ Kenneth W. Street \\ National Aeronautics and Space Administration \\ Glenn Research Center \\ Cleveland, Ohio 44135-3191 \\ Stephen P. Tanner \\ University of West Florida \\ Pensacola, Florida 32514-5751 \\ and \\ Warren H. Philipp \\ National Aeronautics and Space Administration \\ Glenn Research Center \\ Cleveland, Ohio 44135-3191
}

\begin{abstract}
SUMMARY
Atomic spectroscopy has dominated the field of trace inorganic analysis because of its high sensitivity and selectivity. The advantages gained by the atomic spectroscopies come with the disadvantage of expensive and often complicated instrumentation. Solid-phase spectroscopy, in which the analyte is preconcentrated on a solid medium followed by conventional spectrophotometry or fluorometry, requires less expensive instrumentation and has considerable sensitivity and selectivity. The sensitivity gains come from preconcentration and the use of chromophore (or fluorophore) developers and the selectivity is achieved by use of ion exchange conditions that favor the analyte in combination with speciative chromophores. Little work has been done to optimize the ion exchange medium (IEM) associated with these techniques. In this report we present a method for making ion exchange polymer films which considerably simplify the solid-phase spectroscopic techniques. The polymer consists of formaldehyde-crosslinked polyvinyl alcohol with polyacrylic acid entrapped therein. The films are a carboxylate weak cation exchanger in the calcium form. They are mechanically sturdy and optically transparent in the ultraviolet and visible portion of the spectrum, which makes them suitable for spectrophotometry and fluorometry.
\end{abstract}

\section{INTRODUCTION}

During the past few decades, at least 6 review articles (refs. 1 to 6 ) and over 100 papers have appeared in the literature on the subjects of solid-phase spectrophotometry (SPS) and solid-phase fluorometry (SPF). In both SPS and SPF, the analyte is preconcentrated on a solid medium and separated from the original sample matrix, thus enhancing sensitivity and selectivity. Preconcentration is typically done on ion exchange resins, and the subsequent analytical finish uses the ion exchange material as the spectroscopic medium. Both SPS and SPF suffer from scattering and either absorption or emission from the ion exchange material because of the size of the beads (collected by filtration) and the material itself. These problems are minimized or eliminated by the introduction of ion exchange films (refs. 7 and 8), which are transparent throughout the visible and most of the UV region of the spectrum. The background luminescence from the films can be minimized by temporal discrimination for analytes that are long-lived fluorophores or phosphors. 
The ion exchange material (IEM) in film form is a spinoff of a marginal space battery separator developed by NASA in the late 1970's (refs. 9 to 15). In those earlier experiments, a researcher was washing a separator and serendipitously discovered that this material had ion exchange properties. He noticed that washing the film with distilled water caused it to pick up a blue cast, a coloration that was traced to a corroding copper line in the still. This effect was later exploited for the SPS determination of $\mathrm{Cu}^{2+}$ in tap water. To date, the SPS and SPF papers appearing in the literature (with the exception of our earlier report) used commercial resins, but no effort has been made to improve the spectroscopic properties of the ion exchange matrices. Herein, we present details to optimize the production of ion exchange films because they are excellent spectroscopic media and considerably simplify the SPS and SPF techniques.

\section{EXPERIMENT}

Apparatus

Max-Series Electronic Digital Calipers were used to make measurements for area determinations. A Perkin Elmer model 3100 flame atomic absorption spectrometer, equipped with a PC Craft workstation, was used in the normal mode of operation. The $\mathrm{pH}$ meter, a Corning model 130 equipped with combination $\mathrm{pH}$ and automatic temperature compensating electrodes, was used for all pH measurements. A Shimadzu UV 160 recording spectrophotometer, equipped with standard $1-\mathrm{cm}^{2}$ quartz cells and $9-\mathrm{mm}$ quartz spacers, was used to record the visible spectra of nickel, cobalt, and copper ions on ion exchange films. The fluorescence spectrum of gadolinium ions on ion exchange film was taken on a Baird Atomic model FC 100 Fluorichord Spectrofluorometer with slits manually adjusted to optimize signal intensity and resolution. Spectra of films were taken in a triangular cell filled with deionized water such that the film was at a $45^{\circ}$ angle with respect to the excitation and emission slits for the Fluorichord and the cell windows were normal to the entrance and exit of light from the cell.

\section{Chemicals}

Polyvinyl alcohol (PVA, molecular weights of $25000,78000,108000$, and 133000 ) was obtained from Polysciences Inc., and polyacrylic acid (PAA, molecular weights of $250000,450000,750000$, and 3000000 ) from Aldrich Chemical Company. Solutions of polyacrylic acid $(25 \% \mathrm{w} / \mathrm{w}$ in water with molecular weight of 90000 and $50 \%$ w/w with molecular weight of 5000) were also purchased from Aldrich. AR grade formic acid, propionaldehyde that was further diluted to a $25 \% \mathrm{v} / \mathrm{v}$ solution with water, and a $25 \% \mathrm{w} / \mathrm{w}$ solution of glutaraldehyde in water were obtained from Aldrich, and a 37\% w/w solution of AR grade formaldehyde from Fisher Scientific. All metal salts and acids were AR grade chemicals from Fisher Scientific or Mallinckrodt. All solutions were prepared with deionized water.

\section{PROCEDURES}

\section{General Film Casting Procedure}

The film of a 1:1-weight ratio of PVA to PAA was studied. An aqueous polymer solution (10 percent solids) was prepared from stock solutions of PAA (10 percent solids) and PVA (10 percent solids) by stirring in a beaker for $15 \mathrm{~min}$ by hand to ensure complete mixing. The solution was then transferred to a vacuum flask, and a vacuum was pulled over the solution to remove trapped air bubbles. The degassed polymer was then cast onto a lightly waxed, glass-topped table with a 12-in. doctor blade (Gardner Film Casting Knife, AG-4300 series, BYK Gardner, Inc.) set to the desired thickness. The solution was allowed to sit overnight for the water to evaporate. The next day, the dried film was then removed from the glass and cut into smaller easier to handle pieces (approx. $10 \mathrm{by} 10 \mathrm{~cm}$ ). 
The solubilities of each powdered polymer were studied to determine the optimum starting material. A 10-percent-solids solution of either PVA or PAA was prepared by mixing $10 \mathrm{~g}$ of the powder in a beaker with the correct volume of water. The beaker was heated in a hot water bath on a hot plate until all the solid dissolved. A $25 \% \mathrm{w} / \mathrm{w}$ solution in water (molecular weight, 90000 ) and a $50 \% \mathrm{w} / \mathrm{w}$ solution of polyacrylic acid in water (molecular weight, 5000) were also investigated as potential starting materials and were used as received without dilution to 10 percent solids. This study concluded with the selection of the highest molecular weight PVA or PAA that dissolved easily, did not precipitate upon cooling, and remained viscous enough to be easily poured but not run off the casting plate. The optimum film determined from these studies was a 10-percent-solids, 1:1-ratio film of PVA (molecular weight, 180000 )-PAA (molecular weight, 450000 ). In the remainder of this report, "films tested" refers to this optimum variation unless specified otherwise.

\section{Salting Agents}

Salting agents were used to prevent the polymer from dissolving in the aqueous crosslinking reagent prior to the occurrence of the crosslinking reaction. Four solutions were investigated as salting agents (table I). The salting agents were tested by placing approximately 6 - by $6-\mathrm{cm}$ films in a 600 - $\mathrm{ml}$ beaker and adding $350 \mathrm{ml}$ of the salting solution and $150 \mathrm{ml}$ of a crosslinking solution. Formaldehyde was used with salting solutions 1 and 2 and glutaraldehyde with solutions 3 and 4 . After the films were heated in a hot water bath at $70^{\circ} \mathrm{C}$ for $2 \mathrm{hr}$, they were removed and tested to determine the extent of crosslinking. This testing is described in the section Extent of Crosslinking Study.

TABLE I.-SALTING AGENTS

\begin{tabular}{|c|c|c|c|c|c|}
\hline Solution & Salt & $\begin{array}{c}\text { Weight of } \\
\text { salt, } \\
\mathrm{g}\end{array}$ & Catalyst & $\begin{array}{c}\text { Volume of } \\
\text { catalyst, } \\
\text { ml }\end{array}$ & $\begin{array}{c}\text { Water, } \\
\text { ml }\end{array}$ \\
\hline 1 & $\mathrm{CaCl}_{2} \cdot 2 \mathrm{H}_{2} \mathrm{O}$ & 300 & $\mathrm{HCl}$ & 50 & 500 \\
2 & $\left(\mathrm{NH}_{4}\right)_{2} \mathrm{SO}_{4}$ & 250 & $\mathrm{H}_{2} \mathrm{SO}_{4}$ & 15 & 500 \\
3 & $\mathrm{Na}_{2} \mathrm{SO}_{4}$ & 100 & Formic acid & 125 & 500 \\
4 & $\mathrm{CaCl}_{2} \cdot 2 \mathrm{H}_{2} \mathrm{O}$ & 60 & Fomic acid & 25 & 100 \\
\hline
\end{tabular}

\section{Crosslinking Reagents}

After the best salting agent was determined, several chemical crosslinking reagents were tested. Formaldehyde, propionaldehyde, and glutaraldehyde were examined as potential crosslinking agents and were tested by using approximately 6 - by $6-\mathrm{cm}$ films that were placed in $600-\mathrm{ml}$ beakers containing $300 \mathrm{ml}$ of the salting agent and $150 \mathrm{ml}$ of the crosslinking reagent. Table II lists the salting agent-crosslinking reagent combinations that were tested. The beakers were placed in a hot water bath at $70^{\circ} \mathrm{C}$ and were heated for $1 \mathrm{hr}$. Afterwards, the films were removed and tested to determine the extent of crosslinking (see the section Extent of Crosslinking Study). In table II, the salting solution numbers refer to the reagents listed in table I. Hereinafter, the term "crosslinking reagent" refers to the combination of the salting agent and the chemical crosslinker at the concentrations given in table II.

\begin{tabular}{|l|c|c|c|c|c|}
\hline \multicolumn{1}{|c|}{ TABLE II-CROSSLINKING REAGENTS } \\
\hline $\begin{array}{l}\text { Salting } \\
\text { agent }\end{array}$ & $\begin{array}{c}\text { Salt } \\
\text { solution } \\
\text { number }\end{array}$ & $\begin{array}{c}\text { Salt } \\
\text { solution } \\
\text { volume, } \\
\text { ml }\end{array}$ & Crosslinker & $\begin{array}{c}\text { Volume } \\
\text { of cross- } \\
\text { linker, } \\
\text { ml }\end{array}$ & Reagent \\
\hline $\mathrm{CaCl}_{2} / \mathrm{HCl}$ & 1 & 300 & Formaldehyde & 150 & $\mathrm{~A}$ \\
$\mathrm{CaCl}_{2} / \mathrm{HCl}$ & 1 & 300 & Propionaldehyde & 150 & B \\
$\mathrm{CaCl}_{2} / \mathrm{HCl}$ & 1 & 300 & Glutaraldehyde & 150 & $\mathrm{C}$ \\
$\mathrm{CaCl}_{2} /$ formic acid & 4 & (a) & Glutaraldehyde & 50 & D \\
\hline
\end{tabular}

${ }^{8}$ Entire solution from table I. 


\section{Crosslinking Reagent Concentration Optimization}

Several experiments performed to optimize the crosslinking reagent concentration used a 6 - by $6-\mathrm{cm}$ piece of film and exposed it to $300 \mathrm{ml}$ of salt solution 1 (table I) and to either 50,150 , or $200 \mathrm{ml}$ of formaldehyde in a $600-\mathrm{ml}$ beaker. The samples were heated in a hot water bath at $70^{\circ} \mathrm{C}$ for $1 \mathrm{hr}$ and were then removed and tested to determine the extent of crosslinking.

\section{Crosslinking Temperature}

Various hot water bath temperatures used for crosslinking were examined to identify the one that yielded the optimum crosslinked film. Those investigated were 60,70 , and $80^{\circ} \mathrm{C}$ and room temperature (approx. $20^{\circ} \mathrm{C}$ ). The 6- by 6-cm films were exposed to crosslinking reagent A (table II) and were placed in a hot water bath of the specified temperature for $1 \mathrm{hr}$. The film exposed to the crosslinking reagent at room temperature was allowed to sit for $24 \mathrm{hr}$ rather than $1 \mathrm{hr}$. The films were then removed and tested to determine the extent of crosslinking. Their mechanical strength was also tested by pulling and stretching slightly to determine if they would tear.

\section{Crosslinking Time}

Various time increments of exposure to crosslinking reagent $A$ (table II) were investigated to identify the optimum crosslinked film that was clear. Nine films, approximately 6 by $6 \mathrm{~cm}$ and separated by Teflon film, were exposed to the crosslinking reagent in a 600 -ml beaker for 30,60, and $90 \mathrm{~min}$. The beaker was placed in a hot water bath at $70^{\circ} \mathrm{C}$. After each time increment had passed, three films were removed from the beaker, rinsed with deionized water, and stored in 10-percent $\mathrm{NaOH}$. After the films were removed from the $\mathrm{NaOH}$ and rinsed with water, physical properties such as clarity, mechanical strength, and extent of crosslinking were tested. A similar beaker of reagent A with three films was set aside and allowed to sit for $24 \mathrm{hr}$ at room temperature. These films were then removed, stored in 10-percent $\mathrm{NaOH}$, and tested as just described. Similar procedures were followed using the propionaldehyde and the glutaraldehyde solutions, reagents B and C, respectively (table II).

\section{Extent of Crosslinking Study}

After the films were exposed to potential crosslinking reagents, they were tested to determine the extent of crosslinking. After each step in the crosslinking procedure, the 6- by 6-cm films were dried with a Kim Wipe and the final dimensions measured with the digital calipers to determine if swelling had occurred. The films were tested for acceptable mechanical strength by pulling and stretching to determine if they would tear. They were then placed in beakers of water and were boiled on a hot plate for $1 \mathrm{hr}$. Afterwards, the film dimensions, clarity, and mechanical properties were observed again. The goal was to produce a film that would withstand a minimum of $24 \mathrm{hr}$ continuous stirring with a stir bar. Many of the earlier films prepared using unoptimized conditions deteriorated significantly under prolonged stirring.

\section{Film Thickness Study}

The wet polymer solution for the IEM film was cast at different wet thicknesses to determine the optimum thickness. The doctor blade used had a height adjustment capability that altered the wet thickness of the material being cast. The various wet thicknesses examined were $0.5,1.0$, and $2.0 \mathrm{~mm}$. The dried films were then crosslinked by using reagent $A$ for $45 \mathrm{~min}$ at $70^{\circ} \mathrm{C}$, after which they were tested for the extent of crosslinking, clarity, and mechanical strength as described in the previous section.

\section{Conversion to Different Forms}

Three forms of the film (calcium, sodium, and acid) were examined for their effectiveness in removing metal ions. Because the crosslinking takes place in an acidic solution, the film was already in the acid form after the 
crosslinking procedure was completed. The film was placed in a solution of 10-percent $\mathrm{NaOH}$ to be converted to the sodium form. Likewise, that film was placed in a solution containing excess suspended $\mathrm{Ca}(\mathrm{OH})_{2}$ to be converted to the calcium form. A second method for conversion to the calcium form was also investigated. Faintly ammoniacal $\mathrm{CaCl}_{2}\left(1000 \mathrm{ml}\right.$ of $0.5 \mathrm{M} \mathrm{CaCl}_{2}$ and $100 \mathrm{ml}$ concentrated $\left.\mathrm{NH}_{4} \mathrm{OH}\right)$ was placed in a beaker, and the films were added. The $\mathrm{pH}$ of the solution was monitored over several hours to maintain a $\mathrm{pH}$ greater than 9 so that the acid groups on the film would be removed completely. If the $\mathrm{pH}$ dropped below 9, more $\mathrm{NH}_{4} \mathrm{OH}$ was added. The system was monitored until a stable $\mathrm{pH}$ (above 9) was achieved.

\title{
Calcium, Sodium, and Acid Forms
}

All three forms of the film were tested for their effectiveness in removing $\mathrm{Cu}^{2+}$ ions from a standard solution of $15-\mathrm{ppm} \mathrm{Cu} \mathrm{Cu}^{2+}$. For each test, $60 \mathrm{mg}$ of dry-weighed film was placed in a widemouthed glass jar containing $200 \mathrm{ml}$ of 15-ppm Cu${ }^{2+}$ solution in water. A 4-ml sample of the initial solution was acidified with a drop of concentrated $\mathrm{HNO}_{3}$ and set aside for a later determination of the initial concentration of $\mathrm{Cu}^{2+}$ ions. The $\mathrm{pH}$ of the solution was adjusted with dilute $\mathrm{HNO}_{3}$ or $\mathrm{NaOH}$ until the pH stabilized at 5.0. The jars were capped, placed on electronic stirrers, and mixed for $24 \mathrm{hr}$ at $200 \mathrm{rpm}$ with a Fisher 1/2- by 5/16-in. stirring bar. After the full $24 \mathrm{hr}$ of mixing, the films were removed, and the solutions were acidified with $0.1 \mathrm{ml}$ of concentrated $\mathrm{HNO}_{3}$ and were analyzed along with the initial solution by flame atomic absorption spectroscopy (AAS). For each new variation of film (i.e., different wet film thickness or different chemical crosslinking reagents), all three forms of the resin were prepared and tested for their ability to remove $\mathrm{Cu}^{2+}$ ions from solution as just described (see ref. 7 for further details on the $\mathrm{Cu}^{2+}$-IEM system).

\section{Solid-Phase Spectroscopy}

The films used were cut to approximately 1 by $4 \mathrm{~cm}(60 \mathrm{mg})$ from the optimum film formulation and formaldehyde (reagent $A$ ) crosslinking process used on 6 - by 9 -cm pieces of uncrosslinked film. To cover larger pieces of film, it was necessary to increase the volume of formaldehyde to $200 \mathrm{ml}$ in the crosslinking solution. The procedures for sorption of the metal ions on films for SPS and SPF are detailed in the literature (ref. 7). Briefly, the solution containing the metal ion of interest was $\mathrm{pH}$ adjusted and an appropriately sized piece of film equilibrated by gentle stirring. The film was then mounted in the spectrometer cell and the spectra acquired according to conditions given in the captions for the appropriate figures. Absorption and fluorescence emission spectra were acquired on films as described in the text.

\section{RESULTS AND DISCUSSION}

\author{
Film Preparation
}

This project involved the development of a water-insoluble, ion exchange polymer film from two water-soluble materials, PAA and PVA. The film desired for this application was required to be optically clear, consistent, mechanically strong, and thermally stable. The film produced was obtained through numerous optimization experiments. As each experiment was performed, the optimum result was then selected and combined with other optimum results to create such a film.

The components of this new material are two water-soluble polymers (an active ingredient, PAA, and a support polymer, PVA) that were obtained in the powdered form. A solubility study was performed on each powder to determine the ideal starting material. This initial material consisted of a water-based solution of the two ingredients. Since a film was to be cast from this solution, it had to be fluid enough to cast the film but viscous enough to prevent flow after casting on the glass surface. The solubility study of the different molecular weight polymers resulted in the selection of the highest molecular weight polymer that easily dissolved in a solution that was slightly viscous. The higher molecular weight was desirable because it provided a stronger support (PVA) or the active ion exchanger was less likely to leach from the final product (PAA). The wet casting thickness study revealed that $0.5 \mathrm{~mm}$ was too thin to cast the solution and caused tearing of the dried film and difficulties in removing the film from the casting surface. The casting surface was lightly waxed to allow the removal of the dried film that adhered strongly to glass. Attempts to cast the film on Teflon sheet did not produce films because the surface energy of the Teflon was so low that the cast liquid beaded. The $2-\mathrm{mm}$ wet thickness was too thick for this analytical purpose. The optimized mixture 
was a 1:1-weight ratio of 10-percent PVA (molecular weight of 108 000) and 10-percent PAA (molecular weight of 450000 ) that was cast at a wet thickness of $1 \mathrm{~mm}$.

The two polymers used in the ion exchange material (IEM) are naturally water soluble and therefore must be rendered insoluble. Originally, to be crosslinked, the films were radiated (refs. 9 to 15). However, the next step in the development of the films was creating a chemical method to crosslink them so as to facilitate manufacturing in common chemical facilities. The addition of calcium chloride as a salting agent was selected as the best method because the film did not dissolve in water after exposure to the salting agent. The film exposed to solution 2 (ammonium sulfate, sulfuric acid, formaldehyde) did not remain intact when placed in water, which indicated that negligible crosslinking had occurred. The film exposed to solution 3 (sodium sulfate, formic acid, glutaraldehyde) became very brittle, indicating too much crosslinking had occurred. Formaldehyde was chosen as the crosslinking agent because suitable crosslinking was achieved along with desirable physical properties. The propionaldehyde solution achieved little crosslinking and the glutaraldehyde, too much crosslinking. The maximum volume of formaldehyde tested $(200 \mathrm{ml})$ was selected in conjunction with the $300 \mathrm{ml}$ of calcium chloride salting agent because, in addition to producing strong, clear films, this mixture could be filtered and reused. The hot water bath temperature used for the crosslinking procedure was optimized, and a $70^{\circ} \mathrm{C}$ bath was selected because it provided the best crosslinked film. Higher temperature baths resulted in cloudy, brittle films. In comparison, lower temperatures, especially room temperature, extended the time for the films to crosslink, with little or no improvement in the physical properties of the film over those reacted at $70^{\circ} \mathrm{C}$. The time exposed to the crosslinking solution was also a factor in the production of a clear film. A clear film that was produced in $30 \mathrm{~min}$ was not very mechanically durable, whereas those produced after $1 \mathrm{hr}$ of exposure were stronger but cloudy. Therefore, the optimum time of exposure to the crosslinking reagent was determined to be $45 \mathrm{~min}$.

The crosslinking process using formaldehyde is presented in figure 1. The acetal formation involves two alcohol functional groups. Adjacent alcohol functional groups on the same PVA can become involved (path a), and bridging between intermolecular alcohol functional groups (path $b$ ) is also feasible. The film is insoluble because the formed polyvinyl acetal is less soluble than the PVA and intermolecular bridging increases the molecular weight. The film may become more insoluble by the proper choice of an activation cation. The calcium polyacrylate is much less soluble than the corresponding sodium salt or the initial PAA.

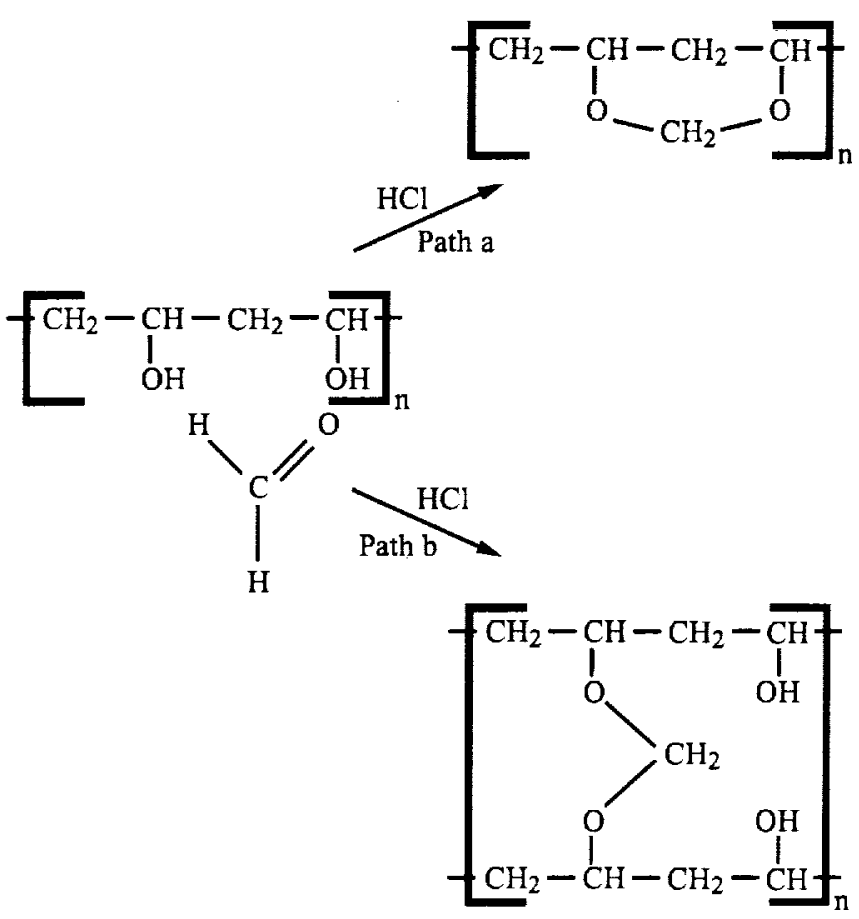

Figure 1.-Formaldehyde crosslinking mechanism. 
Two methods for converting the film to the calcium form were studied. Both were successful; however, the method employing excess calcium hydroxide in water was preferred because it was simpler to use. With the calcium chloride-ammonium hydroxide method, the $\mathrm{pH}$ of the solution had to be monitored continuously and more ammonium hydroxide added if the $\mathrm{pH}$ of the solution dropped below 9. This process was time consuming and therefore less desirable. With an excess of suspended calcium hydroxide, the $\mathrm{pH}$ did not have to be monitored. Conversion of the film to the sodium form caused swelling and led to a deterioration of the mechanical strength. The calcium form actually shrank, which suggested that calcium acts to further crosslink the film at the acid functional groups of the PAA. This type of metal crosslinking may be inter- or intramolecular and is reversible.

\section{SPS and SPF on IEM Films}

Using IEM films rather than powder offers a considerable advantage because the powder must be recovered by filtration, packing it into small cells is problematical, and the refractive indices must be matched to achieve appreciable transmission. The IEM films have a long shelf life. We recovered colored cations on IEM films 6 years ago and with the exception of $\mathrm{Cr}^{3+}$, they do not appear to have degraded during storage. The SPS spectra of $\mathrm{Cu}^{2+}$, $\mathrm{Ni}^{2+}$, and $\mathrm{Co}^{2+}$ appearing in figure 2 were run versus Ca-exchanged IEM film $(60 \mathrm{mg}$ film, $100 \mathrm{ml}$ of approx. $15 \mathrm{ppm}$ of various ions). These cations were collected on 1 - by $4-\mathrm{cm}$ strips of film equilibrated at $\mathrm{pH} 5$ to 6 . Colored photocopies of these films and of $\mathrm{Fe}^{3+}$ and $\mathrm{Cr}^{3+}$ are available through reference 7. Another advantage is that traditional SPS chromophore development reactions can be done on the IEM films. Figure 3 presents the spectrum of the neocuproin (2,9-dimethyl-1,10-phenanthroline) complex from $100 \mathrm{ml}$ of 0.1 -ppm $\mathrm{Cu}^{+}$extracted on the IEM.

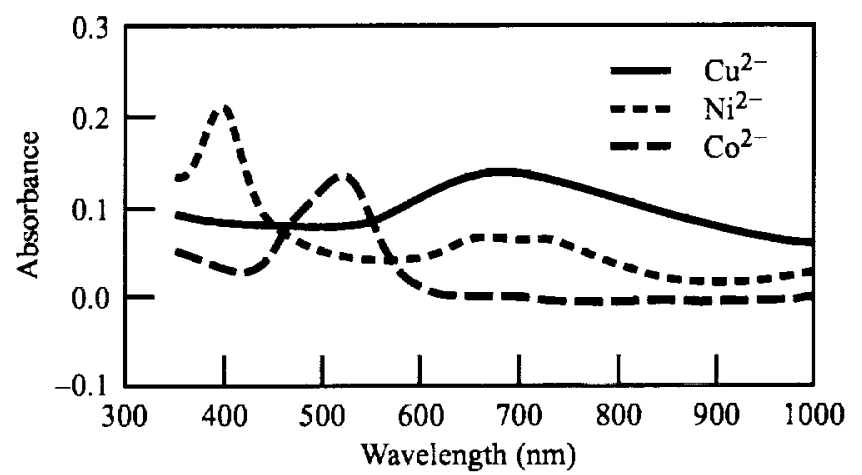

Figure 2.- Solid-phase spectrophotometry spectra (SPS) of $\mathrm{Cu}^{2+}$, $\mathrm{Ni}^{2+}$, and $\mathrm{Co}^{2+}$ extracted on IEM at $\mathrm{pH} 5.5$.

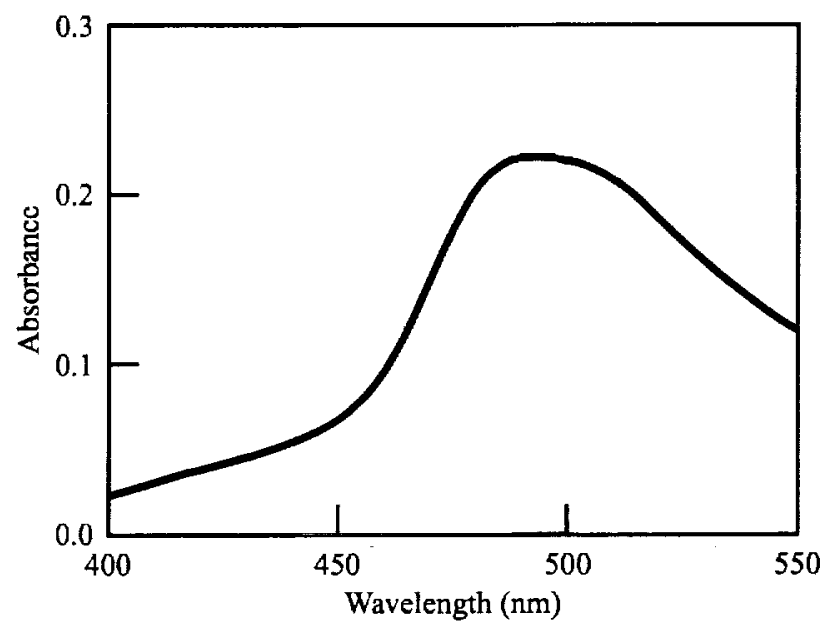

Figure 3.- SPS spectrum of Cu(neocuproin $)_{2}^{+}$complex formed according to literature (ref. 16) and extracted on IEM. 
This spectrum clearly demonstrates the enhancement in sensitivity gained by color development as the absorbance at the analytical wavelength for the complex $(490$ to $500 \mathrm{~nm})$ is almost twice as great as that of $\mathrm{Cu}^{2+}(710 \mathrm{~nm})$ in figure 2. Preliminary data indicate that it is just as feasible to extract $\mathrm{Cu}^{2+}$ onto the IEM followed by reduction to $\mathrm{Cu}^{+}$ with subsequent color development as it is to form the complex in solution and then extract the cationic complex onto the IEM. An interesting system is the complex of S-diphenylcarbazone (DPC) with $\mathrm{Hg}^{2+}$, in that the complex is a water-insoluble neutral species. Figure 4 shows the spectrum of the complex formed by adding alcoholic DPC to a film containing $\mathrm{Hg}^{2+}$. The uncharged complex is retained within the polymer framework which, relative to the aqueous solvent, is hydrophobic and acts as an organic medium. The $\mathrm{Hg}(\mathrm{DPC})_{2}$ complex can also be precipitated from water and extracted to the IEM, yielding similar spectra. Figure 5 shows the spectra of a holmium oxide glass calibration filter and $\mathrm{Ho}^{3+}$ extracted from $100 \mathrm{ml}$ of $30-\mathrm{ppm}$ standard onto $61 \mathrm{mg}$ of IEM at $\mathrm{pH} 5.3$. The

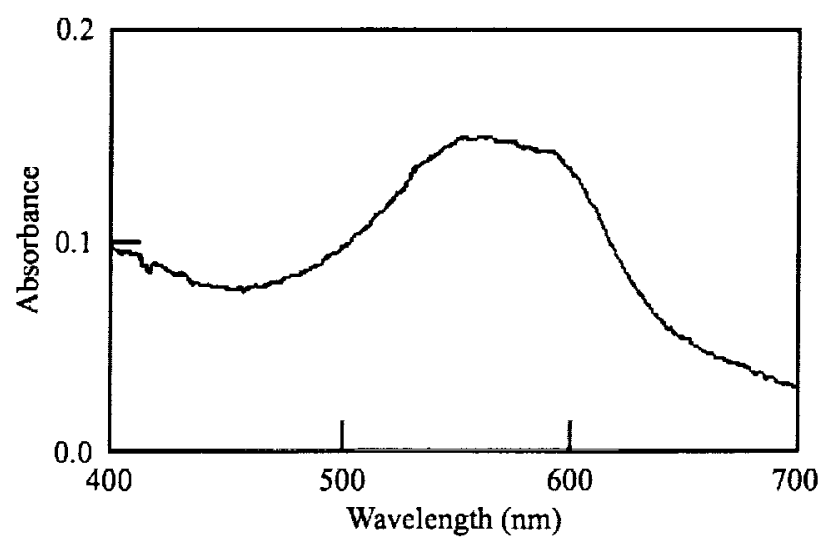

Figure 4.-SPS spectrum of $\mathrm{Hg}(\mathrm{DPC})_{2}$ complex formed on IEM.

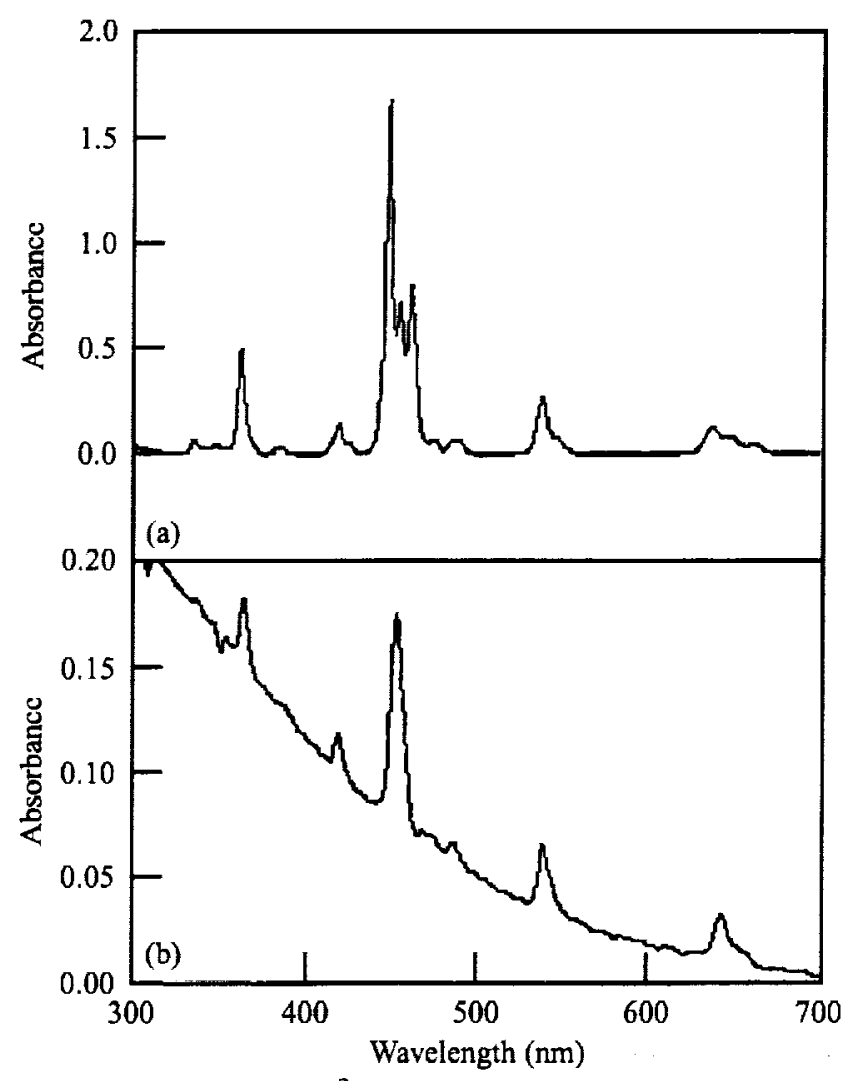

Figure 5.-Spectra of $\mathrm{Ho}^{3+}$. (a) Holmium oxide filter. (b) SPS of $\mathrm{Ho}^{3+}$ on IEM. 


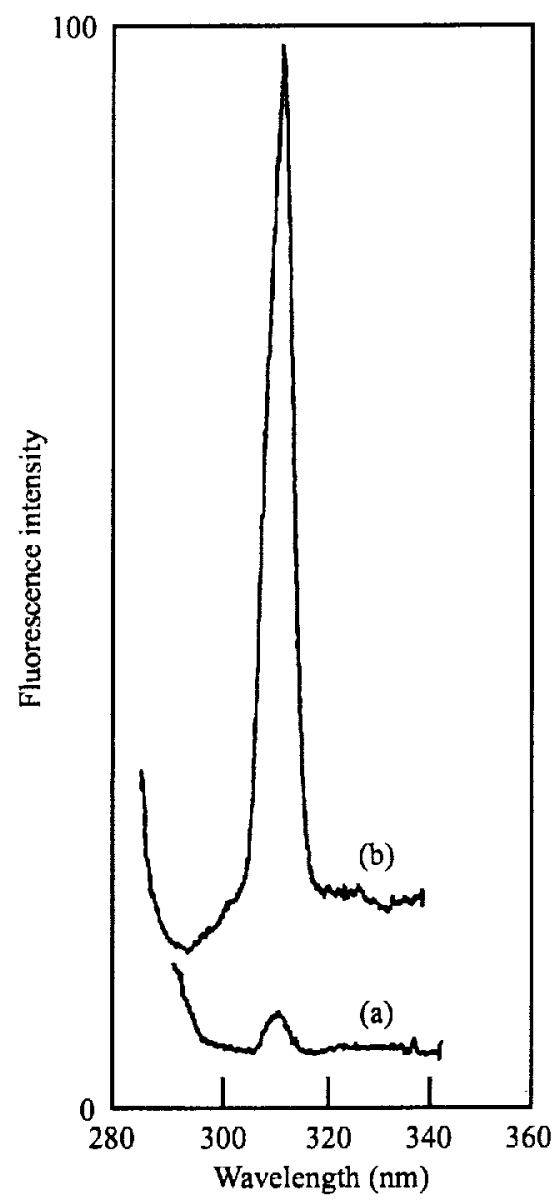

Figure 6.-Fluorescence emission spectra of $\mathrm{Gd}^{3+}$. (a) Solution (1000 ppm). (b) SPF

on IEM.

basic features of the $\mathrm{Ho}^{3+}$ are apparent in the IEM but some of the fine structure is missing due to the difference in $\mathrm{Ho}^{3+}$ coordination between the polymer and glass. Because of the reproducibility of the film and spectra of extracted $\mathrm{Ho}^{3+}$, it should be possible to use this system to prepare inexpensive, disposable wavelength calibration standards. Figure 6 is the SPF fluorescence emission spectra of $\mathrm{Gd}^{3+}$ in solution (1000 ppm) and on IEM (approx. $100 \mathrm{ml}$ of 15 -ppm equilibrated with $60 \mathrm{mg}$ of IEM at $\mathrm{pH} 5.5$ ). Both fluorescence spectra were collected using identical instrument settings, excitation wavelength $(275 \mathrm{~nm})$, excitation and emission spectral slit widths, photomultiplier gain, and so forth to demonstrate the gain in sensitivity associated with preconcentration on IEM films.

\section{CONCLUSION}

This report presented a method for making optically transparent, mechanically strong ion exchange films for solid-phase spectrophotometry (SPS) and solid-phase fluorometry (SPF). The optimized film composition was formed by evaporating a 10-percent-solids aqueous solution, 1:1-ratio of polyacrylic acid (PAA, molecular weight of 450000 ) and polyvinyl alcohol (PVA, molecular weight of 180000 ) cast to a wet thickness of $1.0 \mathrm{~mm}$. The final optimized crosslinking procedure follows: Cut the films to be crosslinked to a size that will fit in a 600 -ml beaker (approx. 6 by $9 \mathrm{~cm}$ ). Place the films in the beaker, separating each film by a piece of $0.4-\mathrm{mm}$-thick Teflon film of the same size. The purpose of the Teflon is to prevent the films from sticking together during the crosslinking reaction. To $200 \mathrm{ml}$ of formaldehyde, add $300 \mathrm{ml}$ of a solution prepared from $300 \mathrm{~g} \mathrm{of} \mathrm{CaCl}, 50 \mathrm{ml}$ of $\mathrm{HCl}$, and $500 \mathrm{ml}$ of water. Completely immerse the IEM films and Teflon in the solution, place the beaker in a $70^{\circ} \mathrm{C}$ hot water bath, and heat for $45 \mathrm{~min}$. Remove the films from the crosslinking solution and rinse them with deionized 
water. The crosslinking solution can then be reused after filtering out any solid matter. The films are then activated by placing them in the appropriate solution for conversion to the desired form, either a 10-percent $\mathrm{NaOH}$ solution for the sodium form or excess suspended $\mathrm{Ca}(\mathrm{OH})_{2}$ for the calcium form. The calcium form is preferred because the equilibrium solution concentration of analyte over the calcium resin is always lower for multivalent ions in combination with its being a more durable material.

\section{REFERENCES}

1. Brykina, G.D.; Krysina, L.S.; and Ivanov, V.M.: Solid-Phase Spectrophotometry. Zh. Anal. Khim., vol. 43, no. 9,1988 , pp. 1547-1560.

2. Capitan, F., et al.: Trace Analysis by Solid Phase Spectrophotometry. Analusis, vol. 19, no. 6, 1991, pp. 177-179.

3. Brykina, G.D.; Marchenko, D.Y.; and Shpigun, O.A.: Solid-Phase Spectrophotometry, J. Anal. Chem. (Transl. of Zh. Anal. Khim.), vol. 50, no. 5, 1995, pp. 440-446.

4. Frenzel, W.: Direct Spectrophotometric Determination of Solid Phase-Absorbed Colored Complexes. GIT Fachz. Lab., vol. 40, no. 7, 1996, pp. 713-714.

5. Waki, H.: "Ion-Exchange Chemistry" in Analytical and Solution Chemistry Researches. Nippon Ion Kokan Gakkaishi, vol. 7, no. 1, 1996, pp. 66-79.

6. Ohashi, K.; and Imura, H.: Spectrophotometric Determination of Inorganic Substances: Highly Sensitive and Selective Chromogenic Reagents. Nippon Bunseki Kagakkai, vol. 3, 1997, pp. 215-223.

7. Hill, C.M., et al.: Determination of Copper in Tap Water Using Solid-Phase Spectrophotometry. NASA TM-106480, 1994.

8. Tanner, S.P.; and Street, K.W.: Solid Phase Luminescence of Several Rare Earth Ions on Ion Exchange Films, NASA TM-208838, 1999.

9. Philipp, W.H.: Polymeric Membrane Systems of Potential Use for Battery Separators, NASA TM X-3567, 1977.

10. Philipp, W.H.; May, C.E.; and Hsu, L-C.: New Ion Exchange Membranes. NASA TM-81670, 1980.

11. Sheibley, D.W.; Manzo, M.A.; and Gonzalez-Sanabria, O.D.: Cross-Linked Polyvinyl Alcohol Films as Alkaline Battery Separators, NASA TM-82802, 1982.

12. Philipp, W.H.; and May, C.E.: Kinetics of Copper Ion Absorption by Cross-Linked Calcium Polyacrylate Membranes. NASA TM-83052, 1983.

13. May, C.E.; and Philipp, W.H.: Search for Selective Ion Diffusion Through Membranes, NASA TM-83426, 1983.

14. May, C.E.; and Philipp, W.H.: Ion Exchange Selectivity for Cross-Linked Polyacrylic Acid, NASA TM-83427, 1983.

15. May, C.E.: Kinetics of Chromium Ion Absorption by Cross-Linked Polyacrylate Films. NASA TM-83661, 1984.

16. Vogel, A.I.: A Text-Book of Quantitative Inorganic Analysis, Third Ed., Lowe \& Brydone Ltd., London, England, 1961. 



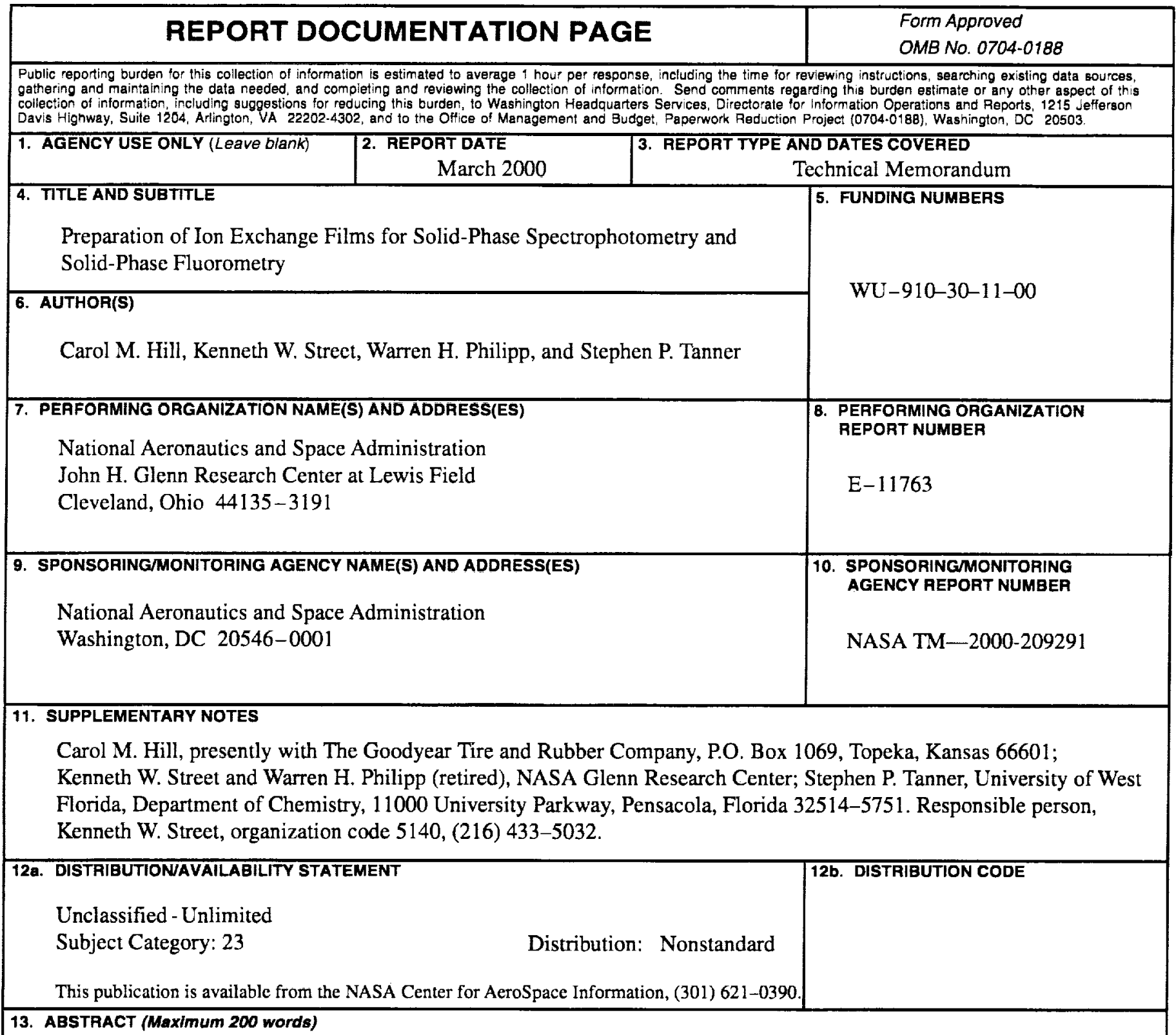

Atomic spectroscopy has dominated the field of trace inorganic analysis because of its high sensitivity and selectivity. The advantages gained by the atomic spectroscopies come with the disadvantage of expensive and often complicated instrumentation. Solid-phase spectroscopy, in which the analyte is preconcentrated on a solid medium followed by conventional spectrophotometry or fluorometry, requires less expensive instrumentation and has considerable sensitivity and selectivity. The sensitivity gains come from preconcentration and the use of chromophore (or fluorophore) developers and the selectivity is achieved by use of ion exchange conditions that favor the analyte in combination with speciative chromophores. Little work has been done to optimize the ion exchange medium (IEM) associated with these techniques. In this report we present a method for making ion exchange polymer films, which considerably simplify the solid-phase spectroscopic techniques. The polymer consists of formaldehyde-crosslinked polyvinyl alcohol with polyacrylic acid entrapped therein. The films are a carboxylate weak cation exchanger in the calcium form. They are mechanically sturdy and optically transparent in the ultraviolet and visible portion of the spectrum, which makes them suitable for spectrophotometry and fluorometry.

14. SUBJECT TERMS

Ion exchange resin; Solid-phase spectrophotometry; SPS; Solid-phase fluorometry; SPF

\begin{tabular}{|c|c|c|}
\hline $\begin{array}{c}\text { 17. SECURITY CLASSIFICATION } \\
\text { OF REPORT } \\
\text { Unclassified }\end{array}$ & $\begin{array}{c}\text { 18. SECURITY CLASSIFICATION } \\
\text { OF THIS PAGE } \\
\text { Unclassified }\end{array}$ & $\begin{array}{c}\text { 19. SECURITY CLASSIFICATION } \\
\text { OF ABSTRACT } \\
\text { Unclassified }\end{array}$ \\
\hline
\end{tabular}

15. NUMBER OF PAGES

16. PRICE CODE

20. LIMITATION OF ABSTRACT 